\title{
EVALUATION OF TWO SEMI-ANALYTICAL TECHNIQUES IN AIR QUALITY APPLICATIONS
}

\author{
JONAS C. CARVALHO ${ }^{1} \&$ DAVIDSON M. MOREIRA ${ }^{2}$ \\ ${ }^{1}$ Universidade Federal de Pelotas, Faculdade de Meteorologia, PPGMET, Pelotas-RS, Brasil \\ E-mail: jonas.carvalho@ufpel.edu.br. Phone: 00555332776690, FAX 00555332776722. \\ ${ }^{2}$ Universidade Federal do Pampa, Centro de Ciência Exatas e Tecnológicas, Bagé-RS, Brasil
}

Received August 2004 - Accepted July 2005

\begin{abstract}
In this article an evaluation of two semi-analytical techniques is carried out, considering the quality and accuracy of these techniques in reproducing the ground-level concentration values of passive pollutant released from low and high sources. The first technique is an Eulerian model based on the solution of the advection-diffusion equation by the Laplace transform technique. The second is a Lagrangian model based on solution of the Langevin equation through the Picard Iterative Method. Turbulence parameters are calculated according to a parameterization capable of generating continuous values in all stability conditions and in all heights of the planetary boundary layer. Numerical simulations and comparisons show a good agreement between predicted and observed concentrations values. Comparisons between the two proposed techniques reveal that Lagrangian model generated more accurate results, but Eulerian model demands a lesser computational time.

Keywords: semi-analytical technique, Eulerian model, Lagrangian model, Laplace transform, Picard Iterative Method, model evaluation.
\end{abstract}

\section{RESUMO: AVALIAÇÃO DE DUAS TÉCNICAS SEMI-ANALÍTICAS EM APLICAÇÕES NA QUALIDADE DO AR.}

Neste artigo é realizada uma avaliação de duas técnicas semi-analíticas, considerando a qualidade e a exatidão destas técnicas em reproduzir valores de concentração ao nível da superfície de poluentes passivos emitidos a partir de fontes baixas e altas. A primeira técnica é um modelo Euleriano baseado na solução da equação advecção-difusão através da técnica de transformada de Laplace. A segunda é um modelo Lagrangiano baseado na solução da equação de Langevin através do Método Iterativo de Picard. Parâmetros da turbulência são calculados de acordo com uma parametrização capaz de gerar valores contínuos em todas as condições de estabilidade e em todas as alturas na camada limite planetária. Simulações numéricas e comparações mostram uma boa concordância entre valores de concentração previstos e observados. Comparações entre as duas técnicas revelam que o modelo Lagrangiano gera resultados mais precisos, mas o modelo Euleriano exige um menor tempo computacional.

Palavras-chave: técnica semi-analítica, modelo Euleriano, modelo Lagrangiano, transformada de Laplace, Método Iterativo de Picard, avaliação de modelos.

\section{INTRODUCTION}

Currently, the search for analytical solutions for the dispersion problems is one of the main research subjects in the pollutant dispersion modelling. These solutions become important due to the intention to obtain dispersion models that generate reliable results in a small computational time, which are of great iterest for regulatory air quality applicarions. Analytical solutions, being the influencing parameters explicitly expressed in a mathematical closed form, allow in general a deep sensitivity analysis over model parameters. Moreover, computer codes based on analytical expressions in general do not have to consider prohibitive computational resources.

Analytical solution for the Eulerian and Lagrangian particle models are usually obtained just for stationary conditions and by making strong assumptions about the wind speed profiles and turbulent parametrizations. In the analytical 
solutions of the diffusion-advection equation they are assumed constant along the whole Planetary Boundary Layer (PBL) or following a power law (van Ulden, 1978; Pasquill and Smith, 1983; Seinfeld, 1986; Tirabassi et al., 1986; Sharan et al., 1996). In Lagrangian particle models, the solution of the Langevin equation is normally obtained according to the rules of the Ito calculus (Rodean, 1996). Some special solutions of the Langevin equation are presented by Gardiner (1985) and Rodean (1996). This last author, for instance, describes the solution for stationary homogeneous turbulence as suggested by Lin and Reid (1963) and Legg and Raupach (1982).

In this paper two semi-analytical techniques are used to simulate the pollutant dispersion during two tracer dispersion experiments. The first technique is an Eulerian model based on a discretization of the PBL in N sub-layers; in each sublayers the advection-diffusion equation is solved by the Laplace transform technique, considering an average value for eddy diffusivity and the wind speed. (Vilhena et al.,1998; Moreira et al.,1999). The second technique is based on solution of the Langevin equation through the Method of Successive Approximations or Picard's Iteration Method (Carvalho et al., 2004, 2005). Lagrangian particle models are obtained considering the Gram-Charlier Probability Density Function (PDF) of turbulent velocity, through which Gaussian and non-Gaussian turbulence conditions can be considered (Anfossi et al., 1997; Ferrero and Anfossi, 1998). The main objective of this paper is to present and discuss the results of a model evaluation between two semi-analytical techniques, focusing the quality and accuracy of these techniques in reproducing the ground-level concentration field of a passive pollutant emitted from low and high sources. Furthermore, this work presents the mathematical and computational features of the Eulerian and Lagrangian models to provide a better understanding about these two techniques.

The turbulent parameters used as input in Eulerian model (diffusion coefficients) and Lagrangian model (velocity fluctuations moments and Lagrangian decorrelation time scales) are parameterized according to a scheme able to generate continuous values in all stability and in all heights in the PBL (Degrazia et al., 2000). Ground-level concentrations measured during Prairie Grass (Barad, 1958) and Copenhagen (Gryning and Lyck, 1984) experiments are used to compare observed and calculated concentrations. The results are evaluated through a statistical analysis ordinarily used to evaluate pollutant dispersion models (Hanna, 1989). The paper is outlined as follows: in section two we present the description of the models, in section three we report the turbulence parameterization, in section four we display the modelling results attained by the two semi-analytical methods and in section five we present the conclusions.

\section{DESCRIPTION OF THE MODELS}

\subsection{Eulerian Model}

Following Vilhena et al. (1998) and Moreira et al. (1999), the steady state advection-diffusion equation is written as (Arya, 1995):

$\mathrm{U}_{\mathrm{i}} \frac{\partial \mathrm{C}}{\partial \mathrm{x}_{\mathrm{i}}}=\frac{\partial}{\partial \mathrm{x}_{\mathrm{i}}}\left(\mathrm{K}_{\mathrm{i}} \frac{\partial \mathrm{C}}{\partial \mathrm{x}_{\mathrm{i}}}\right)$,

where $\mathrm{i}=1,2,3, \mathrm{C}$ denotes the average concentration, $\mathrm{x}_{\mathrm{i}}$ is the position, $U_{i}$ is the mean wind velocity and $K_{i}$ is the eddy diffusivity. The cross-wind integration of the Equation (1), in which the longitudinal axis coincides with the direction of the average wind and the longitudinal diffusion is neglected, leads to:

$\mathrm{U}_{1} \frac{\partial \mathrm{C}_{\mathrm{y}}}{\partial \mathrm{x}_{1}}=\frac{\partial}{\partial \mathrm{x}_{3}}\left(\mathrm{~K}_{3} \frac{\partial \mathrm{C}_{\mathrm{y}}}{\partial \mathrm{x}_{3}}\right)$,

subject to the boundary conditions of zero flux at the ground and PBL top, and a source with emission rate $\mathrm{Q}$ at height $\mathrm{H}_{\mathrm{S}}$ :

$$
\begin{array}{ll}
\mathrm{K}_{3} \frac{\partial \mathrm{C}_{\mathrm{y}}}{\partial \mathrm{x}_{3}}=0 & \text { in } \mathrm{x}_{3}=0, \mathrm{~h} \\
\mathrm{U}_{1} \mathrm{C}_{\mathrm{y}}\left(0, \mathrm{x}_{3}\right)=\mathrm{Q} \delta\left(\mathrm{x}_{3}-\mathrm{H}_{\mathrm{s}}\right) & \text { in } \mathrm{x}_{1}=0,
\end{array}
$$

where now $\mathrm{C}_{\mathrm{y}}$ represents the average cross-wind integrated concentration, $\mathrm{Q}$ is the source term and $\delta$ is the delta Dirac.

Bearing in mind the dependence of the $\mathrm{K}_{3}$ and $\mathrm{U}_{1}$ on the variable $\mathrm{z}$, the height $\mathrm{h}$ of PBL is discretized in $\mathrm{N}$ sub-intervals in such a manner that inside each interval $\mathrm{K}_{\mathrm{z}}(\mathrm{z})$ and $\mathrm{U}(\mathrm{z})$ assume the average value:

$$
\begin{aligned}
\mathrm{K}^{\mathrm{n}} & =\frac{1}{\mathrm{x}_{3}^{\mathrm{n}}-\mathrm{x}_{3}^{\mathrm{n}-1}} \int_{\mathrm{x}_{3}^{\mathrm{n}-1}}^{\mathrm{x}_{3}^{\mathrm{n}}} \mathrm{K}_{3}\left(\mathrm{x}_{3}\right) \mathrm{d} \mathrm{x}_{3} \\
\mathrm{U}^{\mathrm{n}} & =\frac{1}{\mathrm{x}_{3}^{\mathrm{n}}-\mathrm{x}_{3}^{\mathrm{n}-1}} \int_{\mathrm{x}_{3}^{\mathrm{n}-1}}^{\mathrm{x}_{3}^{\mathrm{n}}} \mathrm{U}_{1}\left(\mathrm{x}_{3}\right) \mathrm{dx_{3 }} .
\end{aligned}
$$

Therefore, the solution of problem (2) is reduced to the solution of $\mathrm{N}$ problems of the type:

$\mathrm{U}^{\mathrm{n}} \frac{\partial \mathrm{C}_{\mathrm{y}}^{\mathrm{n}}}{\partial \mathrm{x}_{1}}=\mathrm{K}^{\mathrm{n}} \frac{\partial^{2} \mathrm{C}_{\mathrm{y}}^{\mathrm{n}}}{\partial \mathrm{x}_{3}^{2}} \quad \mathrm{x}_{3}^{\mathrm{n}-1}<\mathrm{x}_{3}<\mathrm{x}_{3}^{\mathrm{n}}$,

for $\mathrm{n}=1: \mathrm{N}$, where $\mathrm{C}_{\mathrm{y}}^{\mathrm{n}}$ denotes the concentration at the $\mathrm{n}^{\text {th }}$ subinterval. To determine the $2 \mathrm{~N}$ integration constants the additional (2N-2) conditions namely continuity of concentration and flux at the interface are considered:

$$
\begin{array}{ll}
\mathrm{C}_{\mathrm{y}}^{\mathrm{n}}=\mathrm{C}_{\mathrm{y}}^{\mathrm{n}+1} & \mathrm{n}=\mathbf{1}, \mathbf{2}, \ldots(\mathrm{N}-\mathbf{1}) \\
\mathrm{K}^{\mathrm{n}} \frac{\partial \mathrm{C}_{\mathrm{y}}^{\mathrm{n}}}{\partial \mathrm{x}_{3}}=\mathrm{K}^{\mathrm{n}+1} \frac{\partial \mathrm{C}_{\mathrm{y}}^{\mathrm{n}+1}}{\partial \mathrm{x}_{3}} & \mathrm{n}=\mathbf{1}, \mathbf{2}, \ldots(\mathrm{N}-\mathbf{1}) .
\end{array}
$$

Applying the Laplace transform in Equation (7) results: 
$\frac{\partial^{2}}{\partial \mathrm{x}_{3}^{2}} \mathrm{C}_{\mathrm{y}}^{\mathrm{n}}\left(\mathrm{s}, \mathrm{x}_{3}\right)-\frac{\mathrm{U}^{\mathrm{n}} \mathrm{s}}{\mathrm{K}^{\mathrm{n}}} \mathrm{C}_{\mathrm{y}}^{\mathrm{n}}\left(\mathrm{s}, \mathrm{x}_{3}\right)=-\frac{\mathrm{U}^{\mathrm{n}}}{\mathrm{K}^{\mathrm{n}}} \mathrm{C}_{\mathrm{y}}^{\mathrm{n}}\left(0, \mathrm{x}_{3}\right)$,

where $\mathrm{C}_{\mathrm{y}}^{\mathrm{n}}\left(\mathrm{s}, \mathrm{x}_{3}\right)=\mathrm{L}_{\mathrm{p}}\left\{\mathrm{C}_{\mathrm{y}}^{\mathrm{n}}\left(\mathrm{x}_{1}, \mathrm{x}_{3}\right) ; \mathrm{x}_{1} \rightarrow \mathrm{s}\right\}$ and $\mathrm{L}_{\mathrm{p}}$ is the operator of the Transform Laplace. The well-known solution of the Equation (10) is (Boyce and DiPrima, 1999):

$C_{y}^{n}\left(s, x_{3}\right)=A^{n} e^{-R^{n} x_{3}}+B^{n} e^{R^{n} x_{3}}+\frac{Q}{2 R_{a}}\left(e^{-R^{n}\left(x_{3}-H_{s}\right)}-e^{R^{n}\left(x_{3}-H_{s}\right)}\right)$

where

$\mathrm{R}^{\mathrm{n}}=\sqrt{\frac{\mathrm{U}^{\mathrm{n}} \mathrm{s}}{\mathrm{K}^{\mathrm{n}}}} \quad$ and $\quad \mathrm{R}_{\mathrm{a}}=\sqrt{\mathrm{U}^{\mathrm{n}} \mathrm{K}^{\mathrm{n}} \mathrm{s}}$.

Finally, applying the interface and boundary conditions we come out with a linear system for the integration constants. Henceforth the concentration is obtained inverting numerically the transformed concentration $\mathrm{C}_{\mathrm{y}}$ by Gaussian quadrature scheme (Heydarian and Mullineaux, 1989):

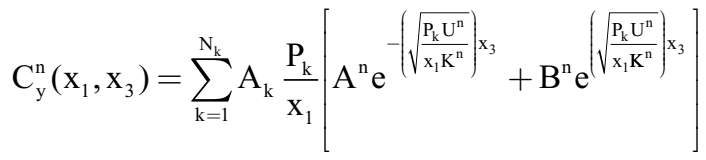

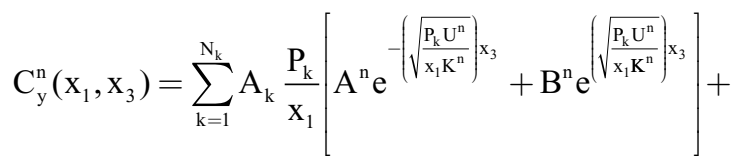

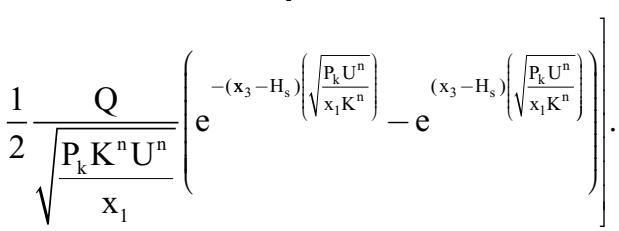

The solution (12) is valid for layers that do not contain the contaminant source and $\mathrm{x}_{1}>0$, once the quadrature scheme of Laplace inversion does not work for and $x_{1}=0$. On the other hand, the solution (13) can be used to evaluate the concentration field in the layer that contains the continuous source. $A_{k}$ and $P_{k}$ are the weights and roots of the Gaussian quadrature scheme and are tabulated in the book by Stroud and Secrest (1966).

\subsection{Lagrangian Model}

An alternative method to solve the Langevin equation based on Picard's Iterative Method was suggested by Carvalho et al. (2004). The three dimensional Langevin equation for inhomogeneous turbulence is:

$\frac{\mathrm{du}_{\mathrm{i}}}{\mathrm{dt}}=\mathrm{a}_{\mathrm{i}}\left(\mathrm{x}_{\mathrm{i}}, \mathrm{u}_{\mathrm{i}}\right)+\mathrm{b}_{\mathrm{i}}\left(\mathrm{x}_{\mathrm{i}}, \mathrm{u}_{\mathrm{i}}\right) \xi_{\mathrm{i}}(\mathrm{t})$,

where $\mathrm{u}_{\mathrm{i}}$ is the turbulent velocity component of each particle, $\mathrm{a}_{\mathrm{i}}\left(\mathrm{x}_{\mathrm{i}}, \mathrm{u}_{\mathrm{i}}\right) \mathrm{dt}$ is the deterministic term, $\mathrm{b}_{\mathrm{i}}\left(\mathrm{x}_{\mathrm{i}}, \mathrm{u}_{\mathrm{i}}\right) \xi_{\mathrm{i}}(\mathrm{t})$ is the stochastic term and $\xi_{\mathrm{i}}$ is a normally distributed (average 0 and variance $\mathrm{dt}$ ) random increment. The displacement of each particle is given by:

$\mathrm{dx}_{\mathrm{i}}=\left(\mathrm{U}_{\mathrm{i}}+\mathrm{u}_{\mathrm{i}}\right) \mathrm{dt}$.

Therefore, the Langevin model consists of a pair of stochastic differential equations that describe the trajectories of neutrally-buoyant "marked particles" in the fluid (Rodean et al., 1992). This formulation includes the well-mixed criterion, which declaretes that if a species of passive "marked particles" is initially mixed uniformly in position and velocity space in a turbulent flow (homogenenous or inhomogeneous), it will stay that way (Thomson, 1987). The particles are not allowed to interact among themselves and no deposition or buoyance effects participe of the dynamic of this model.

In Langevin equation, the deterministic coefficient $a$ depends on the Eulerian PDF of the turbulent velocity and is determined from the Fokker-Planck equation under steady conditions for the statistical momentum (Thomson, 1987; Rodean, 1996). A Gram-Charlier PDF, which is given by the series of Hermite polynomials, can be adopted (Anfossi et al., 1997; Ferrero and Anfossi, 1998). The Gram-Charlier PDF truncated to the fourth order is given by the following expression (Kendall and Stuart, 1977):

$\mathrm{P}\left(\mathrm{r}_{\mathrm{i}}\right)=\frac{\mathrm{e}^{-\left(\mathrm{r}_{\mathrm{i}}^{2} / 2\right)}}{\sqrt{2 \pi}}\left[1+\mathrm{C}_{3} \mathrm{H}_{3}\left(\mathrm{r}_{\mathrm{i}}\right)+\mathrm{C}_{4} \mathrm{H}_{4}\left(\mathrm{r}_{\mathrm{i}}\right)\right]$

where $r_{i}=u_{i} / \sigma_{i}, \sigma_{i}$ is the turbulent velocity standard deviation, $\mathrm{H}_{3}$ and $\mathrm{H}_{4}$ are the Hermite polynomials and $\mathrm{C}_{3}$ and $\mathrm{C}_{4}$ their coefficients obtained according to:

$\mathrm{C}_{\mathrm{m}}=\frac{1}{\mathrm{~m} !} \int_{-\infty}^{+\infty} \mathrm{P}(\mathrm{r}) \mathrm{H}_{\mathrm{m}}(\mathrm{r}) \mathrm{dr}$.

In the case of Gaussian turbulence, Equation (15) becomes a normal distribution, considering $\mathrm{C}_{3}$ and $\mathrm{C}_{4}$ equal to zero. The third order Gram-Charlier PDF is obtained with $\mathrm{C}_{4}=0$.

Applying the Equation (15) in steady Fokker-Planck equation, the deterministic coefficient is given by

$\mathrm{a}_{\mathrm{i}}=\frac{\mathrm{f}_{\mathrm{i}}}{\mathrm{h}_{\mathrm{i}}} \frac{\sigma_{\mathrm{i}}}{\tau_{\mathrm{L}_{\mathrm{i}}}}+\sigma_{\mathrm{i}} \frac{\partial \sigma_{\mathrm{i}}}{\partial \mathrm{x}_{\mathrm{j}}} \frac{\mathrm{g}_{\mathrm{i}}}{\mathrm{h}_{\mathrm{i}}}$,

where $\mathrm{j}$ can assume $1,2,3$ and $\mathrm{j} \neq \mathrm{i}, \tau_{\mathrm{L}_{\mathrm{i}}}$ is the Lagrangian decorrelation time scale and $\mathrm{f}_{\mathrm{i}}, \mathrm{g}_{\mathrm{i}}$ and $\mathrm{h}_{\mathrm{i}}$ are expressions written as:

$$
\begin{aligned}
& \mathrm{f}_{\mathrm{i}}=-3 \mathrm{C}_{3}-\mathrm{r}_{\mathrm{i}}\left(15 \mathrm{C}_{4}+1\right)+6 \mathrm{C}_{3} \mathrm{r}_{\mathrm{i}}^{2}+10 \mathrm{C}_{4} \mathrm{r}_{\mathrm{i}}^{3}-\mathrm{C}_{3} \mathrm{r}_{\mathrm{i}}^{4}-\mathrm{C}_{4} \mathrm{r}_{\mathrm{i}}^{5} \\
& \mathrm{~g}_{\mathrm{i}}=1-\mathrm{C}_{4}+\mathrm{r}_{\mathrm{i}}^{2}\left(1+\mathrm{C}_{4}\right)-2 \mathrm{C}_{3} \mathrm{r}_{\mathrm{i}}^{3}-5 \mathrm{C}_{4} \mathrm{r}_{\mathrm{i}}^{4}+\mathrm{C}_{3} \mathrm{r}_{\mathrm{i}}^{5}+\mathrm{C}_{4} \mathrm{r}_{\mathrm{i}}^{6} \\
& \mathrm{~h}_{\mathrm{i}}=1+3 \mathrm{C}_{4}-3 \mathrm{C}_{3} \mathrm{r}_{\mathrm{i}}-6 \mathrm{C}_{4} \mathrm{r}_{\mathrm{i}}^{2}+\mathrm{C}_{3} \mathrm{r}_{\mathrm{i}}^{3}+\mathrm{C}_{4} \mathrm{r}_{\mathrm{i}}^{4} .
\end{aligned}
$$

Using the deterministic coefficient given by Equation

(17), we can write the Langevin equation as: 
$\frac{d u_{i}}{d t}=\frac{f_{i}}{h_{i}} \frac{\sigma_{i}}{\tau_{L_{i}}}+\sigma_{i} \frac{\partial \sigma_{i}}{\partial x_{j}} \frac{g_{i}}{h_{i}}+\left(\frac{2 \sigma_{i}^{2}}{\tau_{L_{i}}}\right)^{1 / 2} \xi_{i}(t)$,

assuming that $b_{i}=\left(2 \sigma_{i}^{2} / \tau_{L_{i}}\right)^{1 / 2}$ (Hinze, 1975; Tennekes, 1982), where $\sigma_{i}^{2}$ is the turbulent velocity variance.

Rewriting the Equation (19) as

$\frac{d u_{i}}{d t}+\alpha_{i} u_{i}=\beta_{i}+\gamma_{i}+\left(\frac{2 \sigma_{i}^{2}}{\tau_{L_{i}}}\right)^{1 / 2} \xi_{i}(t)$,

where

$\alpha_{\mathrm{i}}=\frac{15 \mathrm{C}_{4}+1}{\mathrm{~h}_{\mathrm{i}} \tau_{\mathrm{L}_{\mathrm{i}}}}, \quad \beta_{\mathrm{i}}=\left[\mathrm{f}_{\mathrm{i}}+\mathrm{r}_{\mathrm{i}}\left(15 \mathrm{C}_{4}+1\right)\right] \frac{1}{\mathrm{~h}_{\mathrm{i}}} \frac{\sigma_{\mathrm{i}}}{\tau_{\mathrm{L}_{\mathrm{i}}}}$ and

$\gamma_{i}=\sigma_{i} \frac{\partial \sigma_{i}}{\partial x_{j}} \frac{g_{i}}{h_{i}}$ it is possible to determine $\exp \left(\int_{\mathrm{t}_{0}}^{\mathrm{t}} \alpha_{\mathrm{i}} \mathrm{ds}\right)$ as the integrating factor
for the Equation $(20)$.

Multiplying the integrating factor by all terms in Equation (20), we obtain an integral equation

$$
\begin{aligned}
& u_{i}=\exp \left(-\int_{t_{0}}^{t} \alpha_{i} d s\right)\left\{\int_{t_{0}}^{t} \exp \left(\int_{t_{0}}^{t^{\prime}} \alpha_{i} d s\right)\right. \\
& \left.\left[\beta_{i}+\gamma_{i}+\left(2 \sigma_{i}^{2} / \tau_{L_{i}}\right)^{1 / 2} \xi_{i}\left(t^{\prime}\right)\right] d t^{\prime}\right\},
\end{aligned}
$$

from which the iterative approximation presents the following form:

$$
\begin{aligned}
& u_{i}^{n+1}=\exp \left(-\int_{t_{0}}^{t} \alpha_{i}^{n} d s\right)\left\{u_{i}^{n}+\int_{t_{0}}^{t} \exp \left(\int_{t_{0}}^{t^{\prime}} \alpha_{i}^{n} d s\right)\right. \\
& \left.\left[\beta_{i}^{n}+\gamma_{i}^{n}+\left(2 \sigma_{i}^{2} / \tau_{L_{i}}\right)^{1 / 2} \xi_{i}^{n}\left(t^{\prime}\right)\right] d t^{\prime}\right\} .
\end{aligned}
$$

The Picard's Iteration Method (Boyce and DiPrima, 1999; page 69) is applied to the Equation (21), assuming that the initial value for the turbulent velocity is a random value supplied by a Gaussian distribution. The Picard Iterative Method or Method of Successive Approximations is a numerical process that can approximate the solution of an initial problem value. The method generates a sequence of functions through a recurrent formula, which converges to the solution of the initial problem value. The sequence of functions obtained through the iterative process converges to a unique solution provided the Lipschitz condition is satisfied, that is, if there is a constant $c$ such that

$$
\left|\mathrm{f}\left(\mathrm{t}, \mathrm{x}_{1}(\mathrm{t})\right)-\mathrm{f}\left(\mathrm{t}, \mathrm{x}_{2}(\mathrm{t})\right)\right| \leq \mathrm{c}\left|\mathrm{x}_{1}(\mathrm{t})-\mathrm{x}_{2}(\mathrm{t})\right|
$$

In principle, the Picard's Iteration Method can be applied to any differential equation, and by this reason is proof of existence and uniqueness of a solution (Innocentini, 1999).

\section{TURBULENCE PARAMETERIZATION}

The present application considers the turbulence parameterization scheme suggested by Degrazia et al. (2000). Accounting for the current knowledge of the PBL structure and characteristics, the authors derived parameterizations for eddy difusivity $\left(\mathrm{K}_{\mathrm{i}}\right)$, turbulent velocity variance $\left(\sigma_{\mathrm{i}}^{2}\right)$ and Lagrangian decorrelation time scale $\left(\tau_{\mathrm{L}_{i}}\right)$ :

$$
\begin{aligned}
& \mathrm{K}_{\mathrm{i}}=0.14 \sqrt{\mathrm{c}_{\mathrm{i}}} \mathrm{z}\left\{\frac{\left(\psi_{\varepsilon}^{\mathrm{c}} \frac{\mathrm{z}}{\mathrm{h}}\right)^{1 / 3}\left(\frac{-\overline{\mathrm{L}}}{\mathrm{h}} \frac{\mathrm{h}}{-\mathrm{L}}\right)^{1 / 2} \mathrm{w}_{*}}{\left[\left(\mathrm{f}_{\mathrm{m}}^{*}\right)_{\mathrm{i}}^{\mathrm{c}}\right]^{4 / 3}}+\frac{\left(\phi_{\varepsilon}^{\mathrm{n}+\mathrm{s}}\right)^{1 / 3} \mathrm{u}_{*}}{\left[\left(\mathrm{f}_{\mathrm{m}}^{*}\right)_{\mathrm{i}}^{\mathrm{n}+\mathrm{s}}\right]^{4 / 3}}\right\} \\
& \hat{\mathrm{i}}_{\mathrm{i}}^{2}=\frac{1.06 \mathrm{c}_{\mathrm{i}}\left(* \mathrm{c} \frac{\mathrm{z}}{\mathrm{h}}\right)^{2 / 3} \mathrm{w}_{*}^{2}}{\left[\left(\mathrm{f}_{\mathrm{m}}^{*}\right)_{\mathrm{i}}^{\mathrm{c}}\right]^{2 / 3}}+\frac{2.32 \mathrm{c}_{\mathrm{i}}(-\mathrm{n}+\mathrm{s})^{2 / 3} \mathrm{u}_{*}^{2}}{\left[\left(\mathrm{f}_{\mathrm{m}}^{*}\right)_{\mathrm{i}}^{\mathrm{n}+\mathrm{s}}\right]^{2 / 3}}
\end{aligned}
$$

and

$$
\tau_{\mathrm{L}_{\mathrm{i}}}=\frac{\mathrm{z}}{\sqrt{\mathrm{c}_{\mathrm{i}}}}\left\{\frac{0.14\left(\frac{-\overline{\mathrm{L}}}{\mathrm{h}} \frac{\mathrm{h}}{-\mathrm{L}}\right)^{1 / 2}}{\left[\left(\mathrm{f}_{\mathrm{m}}^{*}\right)_{\mathrm{i}}^{\mathrm{c}}\right]^{2 / 3} \mathrm{w}_{*}\left(\psi_{\varepsilon}^{\mathrm{c}} \frac{\mathrm{z}}{\mathrm{h}}\right)^{1 / 3}}+\frac{0.059}{\left[\left(\mathrm{f}_{\mathrm{m}}^{*}\right)_{\mathrm{i}}^{\mathrm{n}+\mathrm{s}}\right]^{2 / 3}\left(\phi_{\varepsilon}^{\mathrm{n}+\mathrm{s}}\right)^{1 / 3} \mathrm{u}_{*}}\right\}
$$

where the superscripts $c, n$ and $s$ indicate convective, neutral and stable, respectively, $h$ is the PBL height, $\mathrm{w}_{*}$ is the convective velocity scale, $\mathrm{u}_{*}$ is the local friction velocity, $\psi_{\varepsilon}^{\mathrm{c}}=\varepsilon \mathrm{h} / \mathrm{w}_{*}^{3}$ and $\phi_{\varepsilon}^{\mathrm{n}+\mathrm{s}}=(\varepsilon \kappa \mathrm{z}) / \mathrm{u}_{*}^{3}$ are the nondimensional molecular dissipation rate functions associated to buoyancy and mechanical productions, respectively, $\varepsilon$ is the dissipation rate of turbulent kinetic energy, $\left(\mathrm{f}_{\mathrm{m}}^{*}\right)_{\mathrm{i}}^{\mathrm{c}}$ is the reduced frequency of the convective spectral peak, $\left(\mathrm{f}_{\mathrm{m}}^{*}\right)_{\mathrm{i}}^{\mathrm{n}+\mathrm{s}}$ is the reduced frequency of the neutral or stable spectral peak, $\mathrm{L}$ is the Monin-Obukohv length, $-\overline{\mathrm{L}} / \mathrm{h}$ is an average stability parameter for the convective PBL, in which a typical value of 0.01 is used (this term is introduced in order to give a continuous transition from neutral to convective conditions), $\kappa$ is the Von Karman constant and $c_{i}=\alpha_{i} \alpha_{u}(2 \pi \kappa)^{-2 / 3}$ with $\alpha_{u}=0.5 \pm 0.05$ and $\alpha_{I}=1,4 / 3,4 / 3$ for $\mathrm{u}, \mathrm{v}$ and $\mathrm{w}$ components, respectively.

\section{MODELLING RESULTS}

The performance of the Eulerian and Lagrangian semianalytical models has been evaluated against experimental ground-level concentration provided by the Prairie Grass (Barad, 1958) and Copenhagen (Gryning and Lyck, 1984) diffusion experiments. 


\subsection{Comparison with Prairie Grass Data Set - Unstable Case}

The Prairie Grass experiment was realized in O'Neill, Nebraska, 1956. The pollutant $\left(\mathrm{SO}_{2}\right)$ was emitted without buoyancy at a height of $0.5 \mathrm{~m}$ and it was measured by samplers at a height of $1.5 \mathrm{~m}$ in five downwind distances (50, 100, 200, $400,800 \mathrm{~m})$. The Prairie Grass site was flat with a roughness length of $0.6 \mathrm{~cm}$. The results for twenty convective $(-\mathrm{h} / \mathrm{L}>10)$ experiments are presented. All available data (see Table 1) were used to create a input file for the simulations. Wind speed profile has been parameterized following the similarity theory of Monin-Obukhov and OML model (Berkowicz et al., 1986).

For the simulations, the turbulent flow was assumed inhomogeneous only in the vertical and the transport was realized by the longitudinal component of the mean wind velocity. The horizontal domain was determined according to sampler distances and the vertical one was set equal to the observed PBL height. In Eulerian model, the order of the Gaussian quadrature scheme was $\mathrm{N}_{\mathrm{k}}=8$ because this value provides the desired accuracy with the smallest computational time. The number of sub-layers $\mathrm{N}$ is set according to desired accurate (Moreira et al., 2005); obviously, the greater is $\mathrm{N}$ the more accurate is the calculated concentration pattern, but as a consequence the greater is the relative computational time. In Lagrangian models, the time step was maintained constant and it was obtained according to the value of the Lagrangian decorrelation time scale $\left(\Delta t=\tau_{L} / 10\right)$, where $\tau_{L}$ must be the smaller value between its components. The boundary condition permits reflection of particle velocity at the top and at the bottom of the simulation domain. In Gaussian turbulence case the perfect reflexion is considered and in non-Gaussian turbulence case the scheme suggested by Thomson and Montgomery (1994) is used. Fifty particles were released in each time step during 1000 - 1500 time steps. The concentration field was determined by counting the particles in a cell or imaginary volume. The integration method used to solve the integrals appearing in Equation (21) was the Romberg technique.

The model performances are shown in Tables 4 and 5 and Figures $1 \mathrm{a}$ and $2 \mathrm{a}$. Table 4 shows the result of the statistical analysis made with the observed and predicted values of ground-level cross-wind-integrated concentration $\left(\mathrm{C}_{\mathrm{y}}\right)$. Table 5

Table 1 - Meteorological parameters and concentrations measured during the Prairie Grass unstable experiment. Q is the emission rate and $\mathrm{C}_{\mathrm{y}}$ is the ground-level cross-wind-integrated concentration.

\begin{tabular}{|c|c|c|c|c|c|c|c|c|c|c|}
\hline run & $\begin{array}{l}-\mathrm{L} \\
(\mathrm{m})\end{array}$ & $\begin{array}{c}\text { h } \\
(\mathrm{m})\end{array}$ & $\begin{array}{c}\mathbf{W} * \\
\left(\mathrm{~ms}^{-1}\right)\end{array}$ & $\begin{array}{c}\mathrm{U} 10 \mathrm{~m} \\
\left(\mathrm{~ms}^{-1}\right)\end{array}$ & $\begin{array}{c}Q \\
\left(\mathrm{gs}^{-1}\right)\end{array}$ & $\begin{array}{c}\mathrm{C}_{\mathrm{y}} 50 \mathrm{~m} \\
\left(\mathrm{gm}^{-2}\right)\end{array}$ & $\begin{array}{c}\mathrm{C}_{\mathrm{y}} 100 \mathrm{~m} \\
\left(\mathrm{gm}^{-2}\right)\end{array}$ & $\begin{array}{c}\mathrm{C}_{\mathrm{y}} 200 \mathrm{~m} \\
\left(\mathrm{gm}^{-2}\right)\end{array}$ & $\begin{array}{c}\mathrm{C}_{\mathrm{y}} 400 \mathrm{~m} \\
\left(\mathrm{gm}^{-2}\right)\end{array}$ & $\begin{array}{c}C_{y} 800 \mathrm{~m} \\
\left(\mathrm{gm}^{-2}\right)\end{array}$ \\
\hline 1 & 9 & 260 & 0.84 & 3.2 & 82 & 7.00 & 2.30 & 0.51 & 0.16 & 0.062 \\
\hline 5 & 28 & 780 & 1.64 & 7.0 & 78 & 3.30 & 1.80 & 0.81 & 0.29 & 0.092 \\
\hline 7 & 10 & 1340 & 2.27 & 5.1 & 90 & 4.00 & 2.20 & 1.00 & 0.40 & 0.18 \\
\hline 8 & 18 & 1380 & 1.87 & 5.4 & 91 & 5.10 & 2.60 & 1.10 & 0.39 & 0.14 \\
\hline 9 & 31 & 550 & 1.70 & 8.4 & 92 & 3.70 & 2.20 & 1.00 & 0.41 & 0.13 \\
\hline 10 & 11 & 950 & 2.01 & 5.4 & 92 & 4.50 & 1.80 & 0.71 & 0.20 & 0.032 \\
\hline 15 & 8 & 80 & 0.70 & 3.8 & 96 & 7.10 & 3.40 & 1.35 & 0.37 & 0.11 \\
\hline 16 & 5 & 1060 & 2.03 & 3.6 & 93 & 5.00 & 1.80 & 0.48 & 0.10 & 0.017 \\
\hline 19 & 28 & 650 & 1.58 & 7.2 & 102 & 4.50 & 2.20 & 0.86 & 0.27 & 0.058 \\
\hline 20 & 62 & 710 & 1.92 & 11.3 & 102 & 3.40 & 1.80 & 0.85 & 0.34 & 0.13 \\
\hline 25 & 6 & 650 & 1.35 & 3.2 & 104 & 7.90 & 2.70 & 0.75 & 0.30 & 0.063 \\
\hline 26 & 32 & 900 & 1.86 & 7.8 & 98 & 3.90 & 2.20 & 1.04 & 0.39 & 0.127 \\
\hline 27 & 30 & 1280 & 2.08 & 7.6 & 99 & 4.30 & 2.30 & 1.16 & 0.46 & 0.176 \\
\hline 30 & 39 & 1560 & 2.23 & 8.5 & 98 & 4.20 & 2.30 & 1.11 & 0.40 & 0.10 \\
\hline 43 & 16 & 600 & 1.66 & 6.1 & 99 & 5.00 & 2.40 & 1.09 & 0.37 & 0.12 \\
\hline 44 & 25 & 1450 & 2.20 & 7.2 & 101 & 4.50 & 2.30 & 1.09 & 0.43 & 0.14 \\
\hline 49 & 28 & 550 & 1.73 & 8.0 & 102 & 4.30 & 2.40 & 1.16 & 0.45 & 0.15 \\
\hline 50 & 26 & 750 & 1.91 & 8.0 & 103 & 4.20 & 2.30 & 0.91 & 0.39 & 0.11 \\
\hline 51 & 40 & 1880 & 2.30 & 8.0 & 102 & 4.70 & 2.40 & 1.00 & 0.38 & 0.084 \\
\hline 61 & 38 & 450 & 1.65 & 9.3 & 102 & 3.50 & 2.10 & 1.14 & 0.53 & 0.20 \\
\hline
\end{tabular}


presents the computational time comparison between Eulerian and Lagrangian models. Figure 1a shows the scatter diagram between observed and predicted $\mathrm{C}_{\mathrm{y}}$, where lines have been added to indicate factor of two and factor of three under and over prediction. Figure 2a shows a quantile-quantile plot where the distribution of predicted and observed values are compared. The data are ordered by rank, so for instance the highest observed concentration is paired with the highest predicted concentration (Olesen, 1995). In this sense, this plot permits to compare the frequency distributions of predicted and observed data. The statistical indices in Table 4 are the following (Hanna, 1989):

$$
\begin{aligned}
& \mathrm{NMSE}=\overline{\left(\mathrm{C}_{\mathrm{o}}-\mathrm{C}_{\mathrm{p}}\right)^{2}} / \overline{\mathrm{C}_{\mathrm{o}} \mathrm{C}_{\mathrm{p}}} \\
& \text { (Normalized Mean Square Error) } \\
& \mathrm{FB}=\left(\overline{\mathrm{C}_{\mathrm{o}}}-\overline{\mathrm{C}_{\mathrm{p}}}\right) /\left(0.5\left(\overline{\mathrm{C}_{\mathrm{o}}}+\overline{\mathrm{C}_{\mathrm{p}}}\right)\right) \\
& \text { (Fractional Bias) } \\
& \mathrm{FS}=2\left(\sigma_{\mathrm{o}}-\sigma_{\mathrm{p}}\right) /\left(\sigma_{\mathrm{o}}+\sigma_{\mathrm{p}}\right) \\
& \text { (Fractional Standard Deviation) } \\
& \mathrm{R}=\left(\overline{\mathrm{C}_{\mathrm{o}}-\overline{\mathrm{C}_{\mathrm{o}}}}\right)\left(\mathrm{C}_{\mathrm{p}}-\overline{\mathrm{C}_{\mathrm{p}}}\right) / \sigma_{\mathrm{o}} \sigma_{\mathrm{p}} \\
& \text { (Correlation Coefficient) }
\end{aligned}
$$

$\mathrm{FA} 2=$ fraction of the data for which $0.5 \leq \mathrm{C}_{\mathrm{p}} / \mathrm{C}_{\mathrm{o}} \leq 2$

$$
\text { (Factor of Two) }
$$

where $\mathrm{C}$ is the analyzed quantity (concentration) and the subscripts "o" and " $p$ " represent the observed and the predicted values, respectively. The overbars in the statistical indices indicate averages. The statistical index FB indicates if the predicted quantity underestimates or overestimates the observed one. The statistical index NMSE represents the quadratic error of the predicted quantity in relation to the observed one. The statistical index FS indicates the measure of the comparison between predicted and observed plume spreading. The statistical index FA2 provides the fraction of data for which $0.5 \leq \mathrm{C}_{\mathrm{o}} / \mathrm{C}_{\mathrm{p}} \leq 2$. As nearest zero are the NMSE, FB and FS and as nearest one are the $\mathrm{R}$ and FA2, better are the results.

According Table 4 and 5 and Figures 1a and 2a, the results show a satisfactory agreement between measurements and simulations. NMSE, FB and FS values are relatively near to zero and R and FA2 are relatively near to 1 . The Lagrangian model presents a better performance than Eulerian model when observed and predicted concentration values are compared. However, the computational time required by the Eulerian model to simulate all runs is approximately sixty times lesser.

\subsection{Comparison with Prairie Grass Data Set - Stable Case}

The tracer $\left(\mathrm{SO}_{2}\right)$ was released without buoyancy at a height of $0.5 \mathrm{~m}$ and collected at a height of $1.5 \mathrm{~m}$ at three downwind distances (50,200 and $800 \mathrm{~m})$. The Prairie Grass site was quite flat and much smooth with a roughness length of 0.6 $\mathrm{cm}$. We present here the results for twenty-seven stable runs, for which the condition $\mathrm{h} / \mathrm{L}>0$ is satisfied (see Table 2). The micrometeorological parameters recorded during the dispersion experiments are summarized in Table 3 , based on the paper of van Ulden (1978). The wind speed profile is parameterized following the similarity theory of Monin-Obukhov and OML model (Berkowicz et al., 1986). The numerical and computational characteristics to simulate the Prairie Grass stable experiment were the same used to simulate the unstable one. The results provided by the simulations can be seen in Tables 4 and 5 and Figures $1 \mathrm{~b}$ and $2 \mathrm{~b}$. Like it happened in the unstable Prairie Grass simulation, the Lagrangian model presents accurate results when compared with the ones generated by the Eulerian model. However, the computational effort of the Eulerian model demands a lesser computational time.

\subsection{Comparison with Copenhagen Data Set}

The Copenhagen experiment was carried out in the northern part of Copenhagen. The pollutant $\left(\mathrm{SF}_{6}\right)$ was released without buoyancy from a tower at a height of 115 $\mathrm{m}$ and collected at the ground-level positions in up to three crosswind arcs of tracer sampling units. The sampling units were positioned 2-6 $\mathrm{km}$ from the point of release. The site was mainly residential with a roughness length of $0.6 \mathrm{~m}$. The results for nine runs performed under neutral to convective conditions are presented (see Table 3). Wind speeds at 10 and 115 meters were used to calculate the coefficient for the exponential wind vertical profile. The numerical and computational characteristics to simulate the Copenhagen experiment were the same used to simulate the Prairie Grass experiment. The results provided by the simulations show a very good agreement with measured data. Again, the simulations revealed that, in general, Lagrangian model generates more accurate results, but the simulation time required by the Eulerian model is significantly smaller, as can be seen in Tables 4 and 5 and Figures $1 \mathrm{c}$ and 2c.

\subsection{Mathematical and Computational Analysis}

To a better understanding of the numerical comparison between the Eulerian and Lagrangian semi-analytical methods in this work, our attention is now focused to the mathematical and computational feature of these approaches. Concerning the Eulerian model, it is well known that the results attained by the Gaussian quadrature scheme of order $\mathrm{N}_{\mathrm{k}}$, are exact when the transformed function is a polynomial of degree $\left(2 \mathrm{~N}_{\mathrm{k}}-1\right)$. On the other hand, from the Weierstrass approximation theorem, it is known that a continuous function can be approximated by 
a polynomial, with the property that a better approximation is achieved with the increasing of the degree of the polynomial. This means that increasing $\mathrm{N}_{\mathrm{k}}$ in the Gaussian quadrature schemes appearing in the concentration solution given by Equations (12) and (13), it is expected that the numerical results should converges for the exact result. Concerning the issue of stepwise approximation, it is important to bear in mind that the stepwise approximation of a continuous function converges to the continuous function, when the stepwise of the approximation goes to zero. Therefore, for the Eulerian model it is only necessary to choose the number of the sub-layers in an appropriate manner, by taking the smoothness of the continuous functions $\mathrm{K}_{3}$ and $\mathrm{U}_{1}$ into account.

Concerning to Lagrangian model, it is relevant to consider three main aspects. First, the Langevin equation fulfills the requirements of existence and uniqueness of the solution, what means that Picard's Iterative Method generates a sequence of functions that converges to the exact solution. Second, it is well known that the Picard Method is an iterative process that doesn't depend on the initial guess.

Table 2 - Meteorological parameters and concentrations measured during the Prairie Grass stable experiment.

\begin{tabular}{|c|c|c|c|c|c|c|c|}
\hline run & $\begin{array}{c}\mathrm{L} \\
(\mathrm{m})\end{array}$ & $\begin{array}{c}\text { h } \\
\text { (m) }\end{array}$ & $\begin{array}{c}\mathbf{u}_{*} \\
\left(\mathrm{~ms}^{-1}\right)\end{array}$ & $\begin{array}{l}\text { U 10m } \\
\left(m^{-1}\right)\end{array}$ & $\begin{array}{c}C_{y} 50 \mathrm{~m} \\
\left(\mathrm{gm}^{-2}\right)\end{array}$ & $\begin{array}{c}\mathrm{C}_{\mathrm{y}} 200 \mathrm{~m} \\
\left(\mathrm{gm}^{-2}\right)\end{array}$ & $\begin{array}{c}\mathrm{C}_{\mathrm{y}} 800 \mathrm{~m} \\
\left(\mathrm{gm}^{-2}\right)\end{array}$ \\
\hline 13 & 3.4 & 23 & 0.09 & 3.9 & 38 & 223 & 133 \\
\hline 14 & 1.6 & 12 & 0.05 & 3.7 & 153 & 153 & 31 \\
\hline 17 & 48 & 131 & 0.21 & 3.8 & 105 & 34 & 11 \\
\hline 18 & 25 & 92 & 0.2 & 4 & 108 & 46 & 20 \\
\hline 21 & 172 & 333 & 0.38 & 6.4 & 58 & 18 & 6 \\
\hline 22 & 204 & 400 & 0.46 & 7.7 & 47 & 14 & 4 \\
\hline 23 & 193 & 358 & 0.39 & 6.5 & 47 & 17 & 4 \\
\hline 24 & 248 & 400 & 0.38 & 6.3 & 47 & 15 & 4 \\
\hline 28 & 24 & 81 & 0.16 & 3.2 & 136 & 51 & 15 \\
\hline 29 & 36 & 119 & 0.23 & 4.3 & 99 & 38 & 12 \\
\hline 32 & 8.3 & 43 & 0.13 & 3.6 & 159 & 115 & 56 \\
\hline 35 & 53 & 147 & 0.24 & 4.3 & 88 & 32 & 10 \\
\hline 36 & 7.8 & 36 & 0.1 & 2.8 & 193 & 100 & 41 \\
\hline 37 & 95 & 216 & 0.29 & 5 & 61 & 21 & 7 \\
\hline 38 & 99 & 217 & 0.28 & 4.8 & 78 & 26 & 8 \\
\hline 39 & 9.8 & 48 & 0.14 & 3.6 & 112 & 39 & $9999^{*}$ \\
\hline 40 & 8 & 39 & 0.11 & 3.1 & 115 & 43 & 17 \\
\hline 41 & 35 & 117 & 0.23 & 4.4 & 79 & 32 & 12 \\
\hline 42 & 120 & 275 & 0.37 & 6.3 & 52 & 17 & 5 \\
\hline 46 & 114 & 257 & 0.34 & 5.8 & 63 & 23 & 7 \\
\hline 53 & 10 & 54 & 0.17 & 4.3 & 154 & 83 & 32 \\
\hline 54 & 40 & 128 & 0.24 & 4.5 & 81 & 30 & 11 \\
\hline 55 & 124 & 279 & 0.37 & 6.3 & 53 & 18 & 5 \\
\hline 56 & 76 & 194 & 0.29 & 5.1 & 71 & 24 & 7 \\
\hline 58 & 6.4 & 35 & 0.11 & 3.4 & 161 & 105 & 51 \\
\hline 59 & 11 & 51 & 0.14 & 3.4 & 140 & 81 & 31 \\
\hline 60 & 58 & 166 & 0.28 & 5 & 62 & 23 & 8 \\
\hline
\end{tabular}


Tabela 3 - Meteorological parameters and concentrations measured during the Copenhagen experiment.

\begin{tabular}{ccccccccc}
\hline run & $\begin{array}{c}-\mathbf{L} \\
(\mathbf{m})\end{array}$ & $\begin{array}{c}\mathbf{h} \\
(\mathbf{m})\end{array}$ & $\begin{array}{c}\mathbf{U}_{*} \\
\left(\mathbf{m s}^{-1}\right)\end{array}$ & $\begin{array}{c}\mathbf{U} \mathbf{1 0 ~} \mathbf{m} \\
\left(\mathbf{m s}^{-1}\right)\end{array}$ & $\begin{array}{c}\mathbf{U} \mathbf{1 1 5} \mathbf{~ m} \\
\left(\mathbf{m s}^{-1}\right)\end{array}$ & $\begin{array}{c}\mathbf{Q} \\
\left(\mathbf{g s}^{-1}\right)\end{array}$ & $\begin{array}{c}\text { distance } \\
(\mathbf{m})\end{array}$ & $\begin{array}{c}\mathbf{C}_{\mathbf{y}} \\
\left(\mu \mathbf{g m}^{-2}\right)\end{array}$ \\
\hline 1 & 37 & 1980 & 0.36 & 2.1 & 3.4 & 3.2 & 1900 & 2074 \\
1 & 37 & 1980 & 0.36 & 2.1 & 3.4 & 3.2 & 3700 & 739 \\
2 & 292 & 1920 & 0.73 & 4.9 & 10.6 & 3.2 & 2100 & 1722 \\
2 & 292 & 1920 & 0.73 & 4.9 & 10.6 & 3.2 & 4200 & 944 \\
3 & 71 & 1120 & 0.38 & 2.3 & 5.0 & 3.2 & 1900 & 2624 \\
3 & 71 & 1120 & 0.38 & 2.3 & 5.0 & 3.2 & 3700 & 1990 \\
3 & 71 & 1120 & 0.38 & 2.3 & 5.0 & 3.2 & 5400 & 1376 \\
4 & 133 & 390 & 0.38 & 2.5 & 4.6 & 2.3 & 4000 & 2682 \\
5 & 444 & 820 & 0.45 & 3.1 & 6.7 & 3.2 & 2100 & 2150 \\
5 & 444 & 820 & 0.45 & 3.1 & 6.7 & 3.2 & 4200 & 1869 \\
5 & 444 & 820 & 0.45 & 3.1 & 6.7 & 3.2 & 6100 & 1590 \\
6 & 432 & 1300 & 1.05 & 7.2 & 13.2 & 3.1 & 2000 & 1228 \\
6 & 432 & 1300 & 1.05 & 7.2 & 13.2 & 3.1 & 4200 & 688 \\
6 & 432 & 1300 & 1.05 & 7.2 & 13.2 & 3.1 & 5900 & 567 \\
7 & 104 & 1850 & 0.64 & 4.1 & 7.6 & 2.4 & 2000 & 1608 \\
7 & 104 & 1850 & 0.64 & 4.1 & 7.6 & 2.4 & 4100 & 780 \\
7 & 104 & 1850 & 0.64 & 4.1 & 7.6 & 2.4 & 5300 & 535 \\
8 & 56 & 810 & 0.69 & 4.2 & 9.4 & 3.0 & 1900 & 1248 \\
8 & 56 & 810 & 0.69 & 4.2 & 9.4 & 3.0 & 3600 & 606 \\
8 & 56 & 810 & 0.69 & 4.2 & 9.4 & 3.0 & 5300 & 456 \\
9 & 289 & 2090 & 0.75 & 5.1 & 10.5 & 3.3 & 2100 & 1511 \\
9 & 289 & 2090 & 0.75 & 5.1 & 10.5 & 3.3 & 4200 & 1026 \\
\hline & 289 & 2090 & 0.75 & 5.1 & 10.5 & 3.3 & 6000 & 855 \\
\hline
\end{tabular}

Table 4 - Statistical indices of the model performance for the Prairie Grass and Copenhagen experiments.

\begin{tabular}{lcccccc}
\hline \multicolumn{1}{c}{ Experiment } & Model & NMSE & FB & FS & R & FA2 \\
\hline \multirow{2}{*}{ Prairie Grass - Unstable } & Eulerian & 0.41 & -0.004 & 0.17 & 0.80 & 0.67 \\
& Lagrangian & 0.10 & 0.05 & -0.06 & 0.96 & 0.72 \\
\multirow{2}{*}{ Prairie Grass -Stable } & Eulerian & 0.49 & -0.224 & -0.26 & 0.77 & 0.82 \\
& Lagrangian & 0.39 & -0.057 & -0.18 & 0.81 & 0.95 \\
Copenhagen & Eulerian & 0.08 & -0.12 & 0.15 & 0.86 & 0.91 \\
& Lagrangian & 0.03 & 0.01 & 0.03 & 0.93 & 1.00 \\
\hline
\end{tabular}

Table 5 - Computational time comparison between Eulerian and Lagrangian models.

\begin{tabular}{cccc}
\hline \multirow{2}{*}{ model } & \multicolumn{3}{c}{ computational time (s) } \\
\cline { 2 - 4 } & Prairie Grass - Unstable & Prairie Grass - Stable & Copenhagen \\
\hline Eulerian & 30 & 10 & 10 \\
Lagrangian & 2000 & 600 & 600 \\
\hline
\end{tabular}


a)

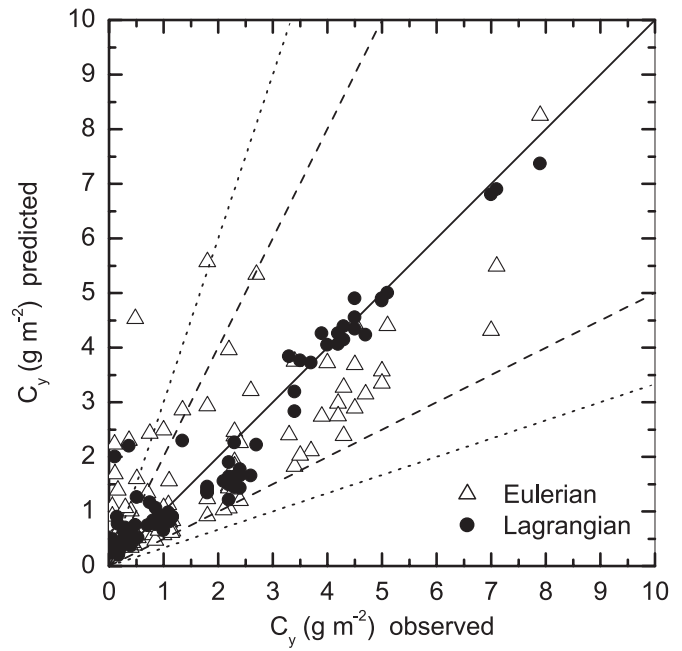

b)

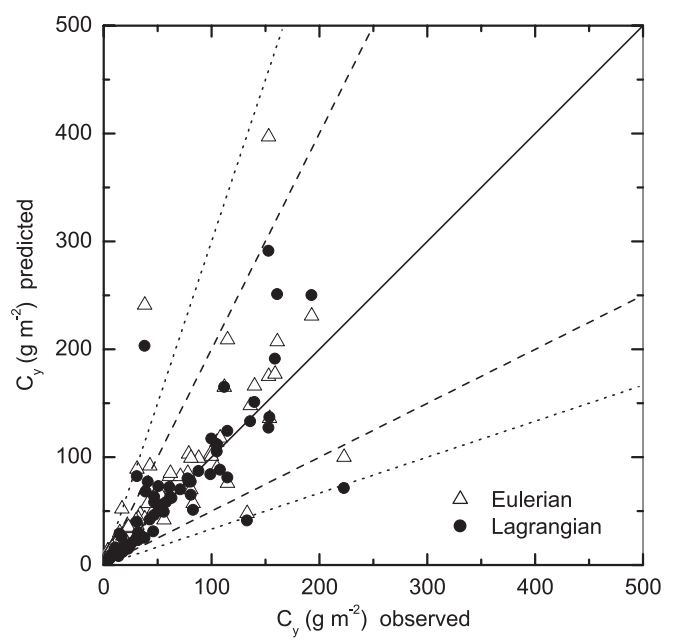

c)

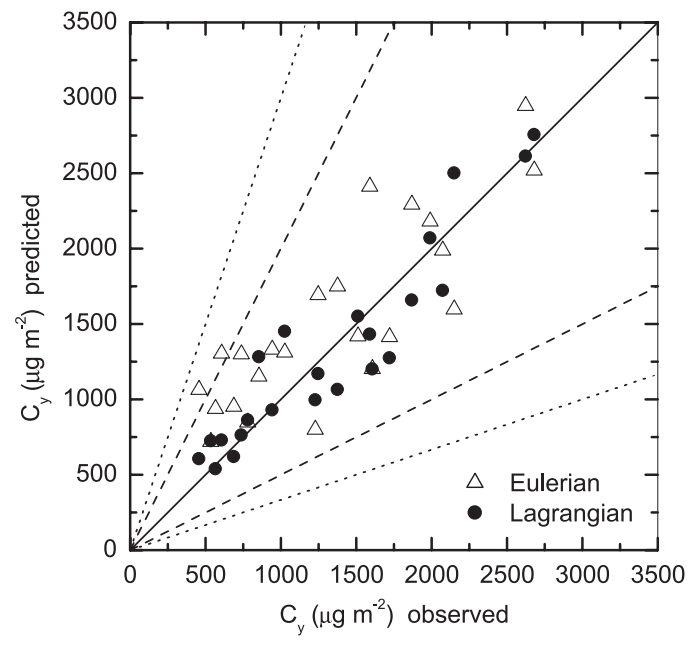

Figure 1 - Scatter diagram between observed and predicted $C_{y}$ for the (a) Prairie Grass unstable (b) Prairie Grass stable and (c) Copenhagen experiments. Dashed lines indicate factor of 2, dotted lines indicated factor of 3 and solid line indicates unbiased prediction. a)

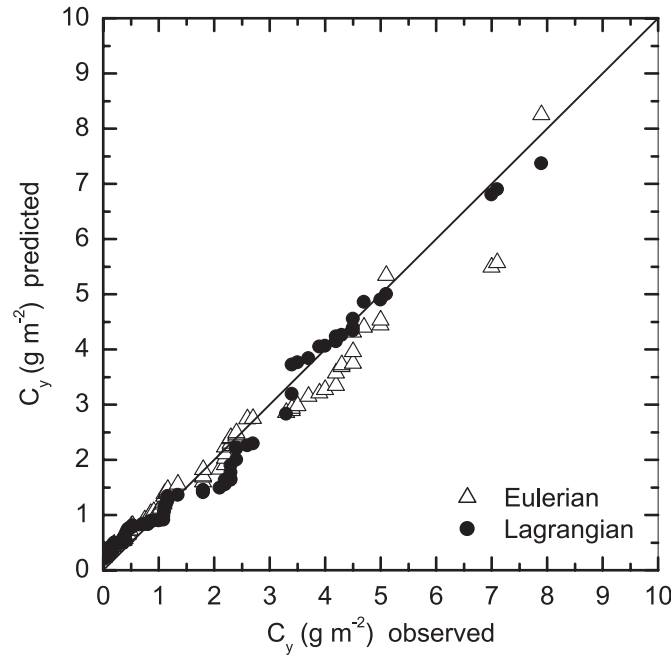

b)

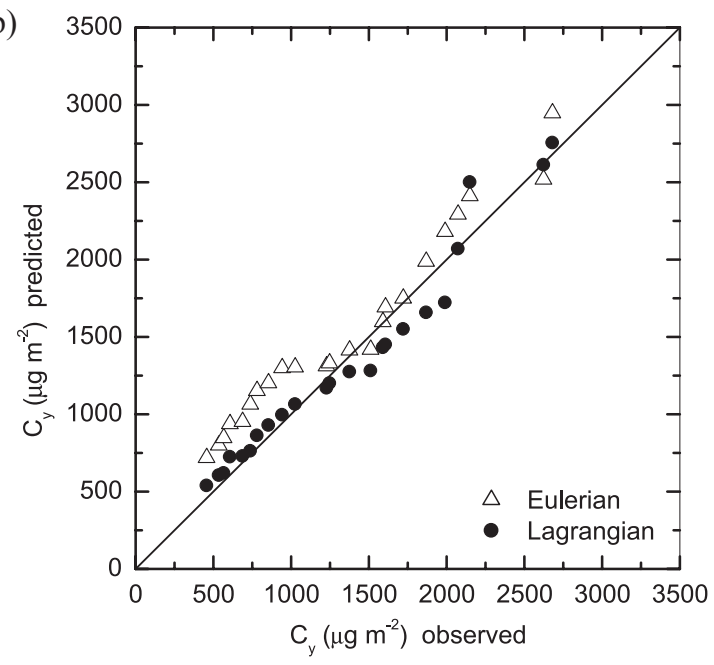

c)

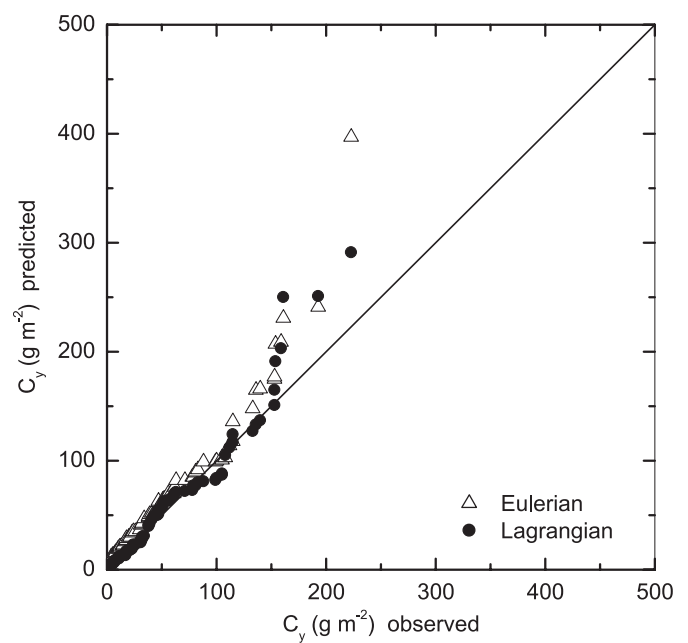

Figure 2 - Model perfomance in terms of quantile-quantile. (a) Prairie Grass unstable, (b) Prairie Grass stable and (c) Copenhagen experiments. Solid line indicates unbiased prediction. 
Third, regarding the analytical feature of the ILS solution in every iterative step, it is possible to control the solution error, except for the round-off error, by regulating the number of iterations. In this sense, we believe that the solution of the Langevin equation through the Picard Method is a promising alternative method in order to simulate the dispersion of pollutants in the PBL. Regarding to extreme computational time compared to Eulerian model, additional development considering other integration techniques has been realized to obtain more satisfactory results.

\section{CONCLUSIONS}

The aim of this paper was to present and discuss the results of an intercomparison between two semi-analytical dispersion model, focusing the ability to correctly reproduce the concentration field of pollutants emitted from low and high sources. An statistical analysis, considering observed and predicted concentration values, revealed that all values for the indices are within ranges that are characteristics of those found for other state-of-the-art models applied to other field datasets, thus showing that the models and the turbulence parameterizations are quite effective. According the results, the Lagrangian model gives more accurate results meanwhile the computational effort of the Eulerian model demands a lesser computational time. This is a promissing result as these two semi-analytical techniques may be jointly used for estimations of contaminant distribution. Neglecting further possible improvement in the Eulerian and Lagrangian models, we can say that these approaches are equivalent, according previous analysis. The method selection for pollutant dispersion simulation has to be done by the user according his necessity and knowledgment. Bearing in mind the semi-analytical character of the mentioned approaches, in the sense that no approximation is made in the derivatives appearing neither in the diffusion equation nor in the Langevin equation and motivated by this semi-analytical feature, we are confident to say that both solutions are exact except for the round-off error.

\section{ACKNOWLEDGEMENTS}

This work was partially supported by CNPq (Conselho Nacional de Desenvolvimento Científico e Tecnológico) and FAPERGS (Fundação de Amparo à Pesquisa do Estado do Rio Grande do Sul).

\section{REFERENCES}

ANFOSSI, D.; FERRERO, E.; SACCHETTI, D.; TRINI CASTELLI, S. Comparison among empirical probability density functions of the vertical velocity in the surface layer based on higher order correlations. Bound.-Layer Meteor. v. 82, p. 193-218, 1997.

ARYA, P.S. Modelling and parameterization of near-source diffusion in weak winds. J. Appl. Met. v. 34, p. 1112-1122, 1995.

BARAD, M.L. 1958. Project Prairie Grass: A Field program in diffusion, Geophys. Res. Paper N ${ }^{0} 59$ (II) TR-58-235 (II), Air Force Cambridge Research Centre, USA.

BERKOWICZ, R.R.; OLESEN, H.R.; TORP, U. The Danish Gaussian air pollution model (OML): Description, test and sensitivity analysis in view of regulatory applications, Air Pollution Modeling and Its Application, C. De Wispeleare, F.A. Schiermeirier and N.V. Gillani Eds..Plenum Publishing Corporation, 453-480, 1986.

BOYCE, W.; DI PRIMA, R. Equações diferenciais elementares e problemas de valores de contorno. Rio de Janeiro: LTC Editora, 1999. 532 p.

CARVALHO, J.C.; NICHIMURA, E.R.; VILHENA, M.T.M.B.; MOREIRA, D.M.; DEGRAZIA, G.A. An iterative langevin solution for contaminant dispersion simulation using the Gram-Charlier PDF, Environmental Modelling and Software v. 20, n. 3, p. 285-289, 2004.

CARVALHO, J. C.; VILHENA, M. T.; MOREIRA, D.M. An alternative numerical approach to solve the Langevin equation applied to air pollution dispersion. Water Air and Soil Pollution, v. 163, n. 1-4, p. 103-118, 2005.

DEGRAZIA, G.A.; ANFOSSI, D.; CARVALHO, J.C.; MANGIA, C.; TIRABASSI, T.; CAMPOS VELHO, H.F. Turbulence parameterization for PBL dispersion models in all stability conditions. Atmos. Environ. v. 34, p. 35753583, 2000.

FERRERO, E.; ANFOSSI, D. Comparison of PDFs, closures schemes and turbulence parameterizations in Lagrangian Stochastic Models. Int. J. Envinm. and Poll. v. 9, p. 384410, 1998. 
GARDINER, C. W. Handbook of stochastic methods for physics, chemistry and the natural sciences. Berlin: Springer-Verlag, 1985.

GRYNING, S.E.; LYCK, E. Atmospheric dispersion from elevated source in un urban area: comparision between tracer experiments and model calculations. J. Climate Appl. Meteor. v. 23, p. 651-654, 1984.

HANNA, S.R. Confidence limit for air quality models as estimated by bootstrap and jacknife resampling methods. Atmos. Environm. v. 23, p. 1385-1395, 1989.

HEYDARIAN, M.; MULLINEAUX, N. Solution of parabolic partial differential equations. Appl. Math. Modelling v. 5, p. 448-449, 1989.

HINZE, J.O. Turbulence. New York: McGraw-Hill, 1975. 790 p.

INNOCENTINI, V. A successive method for the evaluation of trajectories approximating the parcel by a linear function of space and time. Monthly Weather Review v. 127, p. 1639-1650, 1999.

KENDALL, M.; STUART, A. The advanced theory of statistics. New York: MacMillan, 1977.

LEGG, B.J.; RAUPACH, M.R. Markov chain simulation of particle dispersion in inhomogeneous flows: The mean drift velocity induced by a gradient in Eulerian velocity variance. Bound.-Layer Meteor. v. 24, p. 3-13, 1982.

LIN C.C.; REID W.H. Turbulent flow, theroretical aspects. Hand. Physik VIII/2, 438-523, 1963.

MOREIRA, D.M.; DEGRAZIA G.A.; VILHENAM.T. Dispersion from low sources in a convective boundary layer: An analytical model. II Nuovo Cimento, v. 22C, n. 5, 685-691, 1999.

MOREIRA, D. M.; VILHENA, M. T.; CARVALHO, J. C.; DEGRAZIA, G. A. Analytical solution of the advectiondiffusion equation with nonlocal closure of the turbulent diffusion. Environmental Modelling and Software, v. 20, n. 10 , p. $1347-1351,2005$.

OLESEN, H.R. Data set and protocol for model validation. Workshop on Operational Short-Range Atmospheric Dispersion Models for Environmental Impact Assessment in Europe, Mol, Belgium. Int. J. Environm. and Pollution v. 5, n. 4-6, p. 693-701, 1995.
PASQUILL, F.; SMITH, F.B. Atmospheric Diffusion, New York: John Wiley \& Sons, 1983.

RODEAN, H.C.; LANGE, R.; NASSTROM, J.S.; GAVRILOV, V.P. Comparison of two stochastic models of scalar diffusion in turbulent flow. UCRL-JC-110377 Lawrence Livermore National Laboratory, 1992

RODEAN, H.C. Stochastic Lagrangian models of turbulent diffusion. Boston: AMS, 1996. 84 p.

SEINFELD, J.H. Atmospheric Chemistry and Physics of air pollution, New York: John Wiley \& Sons, 1986.

SHARAN, M.; SINGH, M.P; YADAV, A.K. Mathematical model for atmospheric dispersion in low winds with eddy diffusivities as linear functions of downwind distance. Atmos. Environ. v. 30, p. 1137-1145, 1996.

STROUD, A.H.; SECREST, D. Gaussian Quadrature Formulas. Englewood Cliffs: Prentice-Hall, 1996.

TENNEKES H. Similarity relation, scaling laws and spectral dynamics. In: Nieuwstadt F.T.M. and Van Dop H. eds.. Atmospheric Turbulence and Air Pollution Modeling. Reidel, Dordrecht, 37-68, 1982.

TIRABASSI, T.; TAGLIAZUCCA, M.; ZANNETTI, P. KAPPA$\mathrm{G}$, a non-Gaussian plume dispersion model: description and evaluation against tracer measurements. JAPCA v. 36, p. 592-596, 1986.

THOMSON, D.J. Criteria for the selection of stochastic models of particle trajectories in turbulent flows. J. Fluid Mech. v. 180, p. 529-556, 1987.

THOMSON. D.J.; MONTGOMERY, M.R. Reflection boundary conditions for random walk models of dispersion in nonGaussian turbulence. Atmos. Environm. v. 28, p. 19811987, 1994.

van ULDEN, A.P. Simple estimates for vertical dispersion from sources near the ground. Atmos. Environ. v. 12, p. 2125-2129, 1978.

VILHENA, M.T.; RIZZA, U.; DEGRAZIA, G.A.; MANGIA, C.; MOREIRA, D.M.; TIRABASSI, T. An analytical air pollution model: development and evalution. Contribution to Atmospheric Physics v. 71, n. 3, p. 315-320, 1998. 